\title{
A necessidade de consideração da pessoa idosa em potencial estado de alienação parental e a prática de políticas públicas
}

\author{
The need for consideration of the elderly person in a potential state of parental disposition \\ and the practice of public policies
}

\section{La necesidad de consideración de la persona idosa en potencial estado de alienación parental y la práctica de políticas públicas}

Larissa Lauda Burmann ${ }^{1 *}$, Vicente Paulo Alves².

\begin{abstract}
RESUMO
Objetivo: analisar a possibilidade de a pessoa idosa ser vítima de alienação parental. Método: foi realizada pesquisa bibliográfica, de cunho narrativo/crítico, tendo como instrumentos de busca livros jurídicos e periódicos localizados no Pubmed, Bireme-BVS, Scielo, Medline, Lilacs, Scopus e Psyclnfo. Revisão bibliográfica: a pessoa idosa recebeu proteção integral e especial do Estado na Constituição Federal e Lei no 10.741/2003 (Estatuto do Idoso). Porém, não há previsão daquela, ao sofrer violência, em especial, a psicológica, ser considerada vítima de alienação parental. Embora sejam vastos os dispositivos legais, existe uma diferença e, porque não dizer, distanciamento entre leis e eficácia dessas; evidenciando a necessidade de novas políticas públicas em prol da garantia e defesa de direitos das referidas vítimas. Considerações finais: a partir de uma interpretação análoga do art. ํㅡ da Lei ํㅜ 12.318 de 2010 (Lei de Alienação ParentalLAP), uma análise social humanizada, somada à proteção integral aos vulneráveis sociais, será possível considerar a pessoa idosa vítima de alienação parental, quando o ato de violência comprometer a convivência familiar ou seu modo de agir ou pensar.
\end{abstract}

Palavras-chave: Proteção integral da pessoa idosa, Alienação parental, Estatuto do idoso.

\section{ABSTRACT}

Objective: To analyze the possibility of the elderly person being a victim of parental alienation. Method: a bibliographical research was carried out, with a narrative / critical search, with as search tools legal books and periodicals located in Pubmed, Bireme-BVS, Scielo, Medline, Lilacs, Scopus and Psyclnfo. Literature review: the elderly received full and special protection from the State in the Federal Constitution and Law No. 10.741 / 2003 (Statute of the Elderly). However, there is no prediction of this, when suffering violence, especially the psychological, be considered a victim of parental alienation. Although legal provisions are vast, there is a difference and, let alone, distance between laws and their effectiveness, evidencing the need for new public policies to guarantee and defend the rights of those victims. Final considerations: from an analogous interpretation of art. 2 of Law No. 12,318 of 2010 (Parental Alienation Law - PAL), a humanized social analysis, added to the integral protection of the social vulnerable, it will be possible to consider the elderly person victim of parental alienation, when the act of violence compromises the family coexistence or its mode to act or think

Key words: Integral protection of the elderly person, Parental alienation, Status of the elderly.

\section{RESUMEN}

Objetivo: analizar la posibilidad de que la persona de edad sea víctima de enajenación parental. Método: se realizó una investigación bibliográfica, de cuño narrativo / crítico, teniendo como instrumentos de búsqueda en libros jurídicos y periódicos ubicados en el Pubmed, Bireme-BVS, Scielo, Medline, Lilacs, Scopus e Psyclnfo. Revisión bibliográfica: la persona anciana recibió protección integral y especial del Estado en la Constitución Federal y Ley no 10.741 / 2003 (Estatuto del Anciano). Sin embargo, no hay previsión de aquella, al sufrir violencia, en especial, a la psicológica, ser considerada víctima de alienación parental. Aunque son vastos los dispositivos legales, existe una diferencia y, por qué no decir, distanciamiento entre leyes y eficacia

${ }^{1}$ Universidade Federal de Mato Grosso (UFMT), Barra do Garças-MT. *E-mail: laraburmann@hotmail.com

2 Universidade Católica de Brasília (UCB), Brasília-DF. 
de esas; evidenciando la necesidad de nuevas políticas públicas en favor de la garantía y defensa de derechos de dichas víctimas. Consideraciones finales: a partir de una interpretación análoga de la Ley $N^{\circ} 12.318$ de 2010 (Ley de Alienación Parental - LAP), un análisis social humanizado, sumado a la protección integral de las personas vulnerables sociales, será posible considerar a la persona anciana víctima de la alienación parental, cuando el acto de violencia comprometa la convivencia familiar o su modo de vida. actuar o pensar

Palabras clave: Protección integral de la persona mayor, Alienación parental, El estatuto del anciano.

\section{INTRODUÇÃO}

A violência contra pessoa idosa é um tema complexo, multidimensional e intersetorial, constituindo uma barreira na promoção dos princípios constitucionais, como o da dignidade da pessoa humana e igualdade jurídica entre os indivíduos. Os motivos que a antecedem são também consequências das relações sociais e do contexto em que são produzidas, traduzindo em sua maior parte, violação de direitos constitucionais; quais, consequentemente, constam no Estatuto do Idoso - que em 2003 estendeu a proteção especial à esse grupo de vulneráveis, alterando dentre outros, o termo maus-tratos por violência; muito embora, sejam utilizados como sinônimos (MINAYO MCS, 2014).

Em que pese o referido Estatuto ter ampliado os tipos de situações configuradas como violência, deixou algumas lacunas legislativas que enfraquecem o sistema de proteção integral das vítimas, quando por exemplo, à luz da LAP positivou possíveis vítimas de alienação parental - conceituada de forma geral, como a interferência psicológica praticada por genitores - apenas crianças e adolescentes (BRASIL, 2010).

Partindo-se desse entendimento, a pesquisa apresenta o seguinte problema: considerando o conceito de violência, preceituado no art.19, $\S 1$, do Estatuto do Idoso, como "qualquer ação ou omissão praticada em local público ou privado que lhe cause morte, dano ou sofrimento físico ou psicológico vítima de agressão", a pessoa idosa que sofre violência e tenha, por consequência, o ceifamento do seu direito de convivência familiar ou afetação em seu estado psicológico, independentemente do agressor, poderá ser, igualmente, vítima de alienação parental?

Para responder ao referido problema, a pesquisa trata de revisão bibliográfica integrativa da literatura acerca da violência contra pessoa idosa no Brasil, sob um enfoque social e jurídico, em que tece-se considerações sobre a complexidade do que seja a unidade familiar na sociedade contemporânea, suas principais bases principiológicas e o sua responsabilidade, bem como do Estado, frente a vulnerabilidade social das pessoas idosas, alvos fáceis de ataques violentos, inclusive por membros da própria família.

Outrossim, objetiva-se verificar a viabilidade da extensão interpretativa da alienação parental à pessoa idosa, considerando que pessoas em estado de vulnerabilidade social devem receber especial proteção do Estado; inclusive através de ações preventivas pertinentes à violência sofrida por alguns, como a implementação ou mesmo criação de novas políticas públicas capazes de garantir a proteção integral daquelas.

\section{REVISÃO BIBLIOGRÁFICA}

\section{O papel da família contemporânea na proteção integral da pessoa idosa á luz do princípio da dignidade da pessoa humana}

A família, origem da própria civilização, tem sua constituição caracterizada pela imprecisão. Como base sociológica do Estado, encontrando óbices nas manifestações de comprovações fáticas (COELHO FU, 2012), é o núcleo em que repousa a organização social, sendo considerada um grupo natural, que antecede a própria existência do Estado e qualquer modalidade de normatização, ou seja, sua história se mescla com a história da própria humanidade (DIAS MB, 2015).

Assim, ao se escrever sobre família, entra-se em um campo de inúmeras situações complexas que podem aumentar gradativamente de acordo com as relações interindividuais, dissipando princípios éticos e morais. Nesse sentido, grandes modificações, acompanhadas de transformações sociais e científicas, ocorreram nas 
últimas décadas. E, foi assim que a partir do advento da Constituição Federal de 1988 (CF, 1988), art. 226, surgiu uma nova ordem de valores, dedicando proteção especial à assistência familiar, bem como a inserção de novas formas de constituição de família ou entidade familiar, sendo elas: união estável e monoparentalidade, além do casamento.

Entretanto, com novos ideais, a família contemporânea com sustentação e compreensão à luz das garantias constitucionais e, em especial, princípio da dignidade da pessoa humana, entendido como pressuposto da justiça humana, inerente aos indivíduos (ROCHA CLA, 2016), presente no art. $1^{\circ}$, III, da $\mathrm{CF} / 88$, tem delineado um processo de democratização famliar, pautada na igualdade de gêneros, na convivência familiar, no pluralismo das relações familiares merecedoras de proteção, não mais restritas às constantes no referido diploma legal, como é o caso das famílias homoafetivas. O caráter formal e absolutizado tem cedido espaço para um núcleo social funcionalizado ao desenvolvimento da personalidade e da dignidade de seus membros, justificando sua própria existência e proteção estatal (TEIXEIRA ACB e RODRIGUES RL, 2015).

Assim, sobreleva-se o princípio da dignidade da pessoa humana como nicho informador do Estado Democrático de Direito, tendo por um de seus objetivos garantir o desenvolvimento de seus membros (GONÇALVES CR, 2015).

Corroborando com o referido princípio, no sentido de ser instrumento capaz de reorientar normas legais pertinentes aos indivíduos e à sua realização pessoal, valorizando o ser em detrimento do ter, ou seja, o patrimônio deixa a centralidade de outrora, urge o princípio da solidariedade social, que trata da ação humanitária em que um ou um grupo de indivíduo zela, presta ajuda e respeita os demais, tanto na esfera patrimonial, como psicológica e afetiva. Dessa forma, são verificadas duas dimensões: uma interna, face a necessidade de ajuda mútua e o estabelecimento de deveres entre os membros de um grupo familiar; e a externa, existente nas relações estabelecidas entre grupos familiares com a sociedade e o Estado, muito embora, esse último tenha a obrigação de assegurar a assistência à família na pessoa de cada um de seus membros, criando mecanismos capazes de coibir, por exemplo, atos de violência, consagrando a solidariedade social na ótica familiar (LÔBO P, 2011).

Nesse sentido, mesmo que grupos de vulnerávais tenham em seus Estatutos garantias de proteção integral e convivência familiar, como no art. $3^{\circ}$ do Estatuto do Idoso que preve ser " (...) obrigação da família, da comunidade, da sociedade e do Poder Público assegurar ao idoso, com absoluta prioridade, a efetivação do direito à vida, à saúde, à alimentação, à educação, à cultura, ao esporte, ao lazer, ao trabalho, à cidadania, à liberdade, à dignidade, ao respeito e à convivência familiar e comunitária", costumeiramente tem-se atribuído primeiro a família e, posteriormente, ao Estado a referida obrigação, refletindo uma relação de subsidiariedade entre grupos familiares e o Estado para provimento de direitos assegurados aos indivíduos (MINAYO MCS, 2014).

Entretanto, princípios e normas constitucionais não são autoaplicáveis, sendo que algumas vezes, as normas especiais apresentam-se ineficazes, pelos mais diversos motivos, cumprindo à família, sociedade e Estado assegurarem os direitos fundamentais daqueles que necessitam de proteção integral, esculpindo na ordem jurídica nacional valores de tolerância e pluralismo de sujeitos (BELLO FILHO NB, 2003).

É no bojo dessas considerações que a questão da violência contra pessoa idosa tende a ser deslocada da esfera privada, familiar, para pública e exigindo respostas dinâmicas do Estado e da sociedade em prol da efetividade de instrumentos de combate àquela.

\section{A pessoa idosa em potencial estado de alienação parental}

Um tema bastante complexo é a conceituação ou mesmo delimitação do que seja a violência contra a pessoa idosa, fácil alvo de ataques violentos, oriundos dos mais diversos fatores, sejam eles individuais, de relacionamentos, comunitários, sociais, dentre outros.

Sobre a referida, um dos principais marcos legislativos é a Organização Mundial de Saúde (OMS), qual a definiu como a ameaça ou prática, com emprego de força física ou poder, contra si próprio ou em desfavor 
de outra (s) pessoa (s), passível de gerar sofrimento, morte, dano psicológico, desenvolvimento prejudicado ou privação. A referida acabou por relacionar intenção à realização do ato, independentemente do resultado, excluindo por exemplo, atos não intencionais. Ainda, solicitada pela Assembleia Mundial da Saúde (World Health Assembly), classificou violência sob três formas: violência dirigida a si mesmo (auto infligida); violência interpessoal e violência coletiva (OMS, 2002).

A violência interpessoal refere-se à violência comunitária, verificada entre pessoas sem laços de parentesco; e violência da família e de parceiro(a) íntimo(a), podendo ocorrer também fora de casa, como por exemplo, abuso contra pessoas idosas. Quanto a essas vítimas de violência, ressalta-se que são sobretudo mulheres, solteiras e com baixa escolaridade, possuindo algum tipo de dependência física ou psicológica, que compartilham convivência com filhos, noras e netos (CASTRO VC, et al, 2018), fato que poderá auxiliar na inibição da revelação de atos de violência às autoridades estatais ou membros da própria família, pelos mais diversos motivos, como o sentimento de medo de exclusão familiar. Portanto, não é forçoso visualizar a alienação sofrida pela pessoa idosa, tolhida da convivência familiar, quando a motivação do afastamento foi promovida por familiar, configurando uma forma perversa de desumanização.

Já a violência coletiva está subdividida em violência social, política e econômica, quais aduzem a existência de motivos possíveis para a violência cometida pelos grandes grupos de pessoas ou pelo Estado. A exemplo da violência política, atrealada a carência de recursos materiais, citam-se as Instituições de Longa Permanência para Idosos (ILPI's) e demais organizações previstas em estautos e leis complementares, quando apresentam infraestrutura precária, mão de obra desqualificada, dificuldades financeiras, entre outros (DAHLBERG LL e KRUG EG, 2006).

Respeita a classificação referida, Minayo MCS (2014), entende que a violência contra idosos poderá ser manifestada de três formas, quais sejam: (a) estrutural (originária da desigualdade social); (b) familiar (originárias de relações cotidianas); e, (c) institucional (originária de atos e omissões do Poder Público); gerando um variado rol de consequências, ressaltando aos pesquisadores e sociedade como um todo, a necessidade de ser estudada a violência não apenas física, mas também aquelas que de alguma forma interferem em um primeiro momento na psique do indivíduo.

Em consonância com a tipologia referida, em nível nacional, a violência contra pessoa idosa passou a ser enfatizada nas duas últimas décadas, recebendo a contribuição de movimentos sociais e governamentais, quais refletiram na promulgação da Política Nacional do Idoso em 1994 e no Estatuto do Idoso em 2003 que definiu, em seu art. 19, $\S 1$ o , o conceito de violência, conforme segue: “( ...) considera-se violência contra $o$ idoso qualquer ação ou omissão praticada em local público ou privado que the cause morte, dano ou sofrimento físico ou psicológico". Ainda, declarou que maus-tratos ou atos de violência - muitas vezes utilizados como sinônimos - deferidos à pessoa idosa geram violação de direitos; sendo normatizada a proteção dos indivíduos, dispensando tratamento especial, refletindo uma preocupação em nível mundial.

Nesse sentido, coube à Política Nacional de Redução de Acidentes e Violências designar várias formas de violência contra idosos, dentre elas: física, psicológica, sexual, econômica, abandono e negligência, visíveis ou até mesmo invisíveis aos olhos humanos, quais os colocam em situação de vulnerabilidade social. Com relação à vulnerabilidade social da pessoa idosa, a priori, deve-se considerar que a senectuede faz parte do processo de envelhecimento humano, consitutindo um estado de inferioridade e desgaste não patológicos, não justificando em um primeiro momento, qualquer interdição (MADALENO R, 2017).

Portanto, o processo de envelhecimento e velhice devem ser compreendidos como complementares e indissociáveis, que variam de acordo com os contextos sociais, econômicos e políticos em que o indivíduo está inserido, ou seja, ligam-se a questões existenciais. Estas, por sua vez, implicam na condição natural da vulnerabilidade social da pessoa idosa, podendo ser compreendida sob dois enfoques, individual, construído sob diferentes influências de ordem sociocultural, tais como: acesso a oportunidades educacionais, adoção de cuidados em saúde; e, coletivo, implicando nas diversas trajetórias de vida (LIMA AMM, et al, 2008).

Dessa forma, as pessoas idosas constituem um grupo social de vulneráveis que estão à mercê da violência, muitas vezes com limitações físicas e cognitivas, oriundos da senilidade e senescência. Para tanto, 
na literatura tem-se discutido acerca da possibilidade de considerar a pessoa idosa - que sofre violência e tenha, de alguma forma, atingida sua psquie - vítima de alienação parental à luz de uma interpretação análoga do artigo $2^{\circ}$ LAP (BRASIL, 2010), que preceitua:

\section{Art. 2 o Considera-se ato de alienação parental a interferência na formação psicológica da criança ou do adolescente promovida ou induzida por um dos genitores, pelos avós ou pelos que tenham a criança ou adolescente sob a sua autoridade, guarda ou vigilância para que repudie genitor ou que cause prejuízo ao estabelecimento ou à manutenção de vínculos com este.}

Cumpre ressaltar que a alienação parental poderá ser compreendida como forma de abuso emocional que envolve três sujeitos, quais sejam: alienador, vítima e alienado; é exteriorizada pela interferência que crianças e/ou adolescentes (vítimas) recebem em sua formação psicológica promovida ou induzida por um dos genitores ou responsável (alienador) para que repudie ou cause prejuízo ao estabelecimento ou à manutenção de vínculos com outro genitor (alienado), não podendo ser confundida como a síndrome da alienação parental que é o resultado da conduta do alienante (GARDNER RAMD, 2002).

Diante do exposto, a LAP é um meio jurídico que tem como uma de suas finalidades atenuar ou mesmo extinguir os efeitos da síndrome da alienação parental, protegendo os direitos fundamentais de indivíduos em situação de vulnerabilidade social, em especial, o direito a convivência familiar. Favretto A (2006) explica que para alguns profissionais, como por exemplo, a psicóloga clínica Larissa Canan, o fato de a alienação estar relacionada a redução da capacidade civil de manifestação livre de vontade dos indivíduos de pensar ou mesmo agir, poderá ser verificada tanto em crianças e adolescentes quanto nas pessoas idosas, quando por exemplo, essas desprovidas de capacidade decisória, agirem imbuídas por atos coativos do agente alienador.

Entretanto, a sua extensão às pessoas idosas vítimas de violência já referida, encontra óbcies em meio a um vasto sistema legislativo e de política públicas, em prol da proteção integral dos grupos de vulneráveis, mas com lacunas legislativas; considerando que na literalidade normativa não há punição àquele que influencia, de forma dolosa, na forma de pensar e agir da pessoa idosa. Seguindo a literalidade da norma, Zimmermann A (2002), entende que a LAP é direcionada a proteção integral dos menores e a interpretação gramatical da norma é clara, não existindo possibilidade de extensão da aplicabilidade, evitando atos de juízes que extrapolem os limites constitucionais impondo preferências, fazendo-se valer de fundamentos retirados do devido processo legal.

Entretanto, comparando casos de violência contra a pessoa idosa, crianças e adolescentes, que impliquem no tolhimento de convivência familiar e violação de integridade psicológica, denota-se dentre tantas, semelhança quanto ao bem que se busca tutelar. Dessa forma, por uma questão de justiça a aplicação análoga da LAP apresenta-se como alternativa à proteção das pessoas que se encontram em situação de vulnerabilidade que faz emergir uma nova forma de interpretação e aplicação legislativa, mais humanizada, sendo imprescindível a atuação do Poder Judiciário na garantia e promoção do princípio da dignidade da pessoa humana (MARQUES CL e MIRAGEM BO, 2014).

Nesse sentido, recentemente o Tribunal de Justiça do Rio Grande do Sul, embora não tenha apreciado o mérito, através do julgamento do Agravo de Instrumento № 70076907096, analisou recurso em que uma das partes buscava aplicação analógica da Lei 12.318/2010, em prol proteção do idoso, sob o fundamento de que a legislação não dispõe de mecanismos adequados ao caso.

Estabelecendo uma conexão entre a interpretação abstrata ao caso concreto, Gomes JLP (2014), entende que o rol esculpido no art. $2^{\circ}$ da LAP não é taxativo, sendo atribuído ao poder judiciário, diante de casos concretos, deliberar sobre interpretação extensiva do referido artigo. Não obstante às pesquisas acerca da analogia, Souza VS e Oliveira PO (2018) entendem que casos comuns não podem partir de ocorrências taxativas. Considerando a existência de um rol exemplificativo de formas de alienação parental, constante no parágrafo único do artigo $2^{\circ}$ da LAP, abre-se possibilidade ao juiz do caso concreto declarar demais casos, verificados por perícia ou outro meio legal, não havendo objeção quanto a extensão da referida lei às pessoas idosas. 
Salienta Bello Filho NB (2003) que o sistema constitucional é aberto, sendo composto pela realidade e o texto; embora interpretado, não poderá haver redução; assim, em atenção a vulnerabilidade da vítima, seria possível a interpretação extensiva da LAP, no intuito garantir os direitos fundamentais da pessoa idosa, conforme já referido. Corroborando com sistema aberto, Moraes MCB (2010) afirma que os valores e princípios constitucionais são responsáveis pela determinação de normas legislativas e interpretativas aplicadas ao caso concreto, composto tanto de relações interindividuais como coletivas, envolvendo o próprio Estado.

Outrossim, o artigo $5^{\circ}$ da Lei de Introdução às Normas de Direito Brasileiro (BRASIL,1942) ao determinar que "na aplicação da lei, o juiz atenderá aos fins sociais e às exigências do bem comum", acaba por garantir uma releitura da legislação civil à luz da Constituição Federal. Dessa forma, o intérprete ao completar o proposto pelo legislador, poderá sofrer as influências dos mais variados valores sociais, legais, econômicos, políticos etc.

Ainda sob um enfoque sociológico é possível a referida interpretação, posto que assim como crianças e adolescentes, a pessoa idosa, constitucionalmente, consta no rol das pessoas que devem receber especial e integral proteção do Estado, devendo seus direitos ser resguardados e alcançados sem discriminação em virtude da posição de vulnerabilidade, conforme já referido. Entretanto, ressalta-se que enquanto a alienação parental sofrida por crianças e adolescentes é carreada de sentimentos, o mesmo não necessariamente irá ocorrer quando as vítimas forem pessoas idosas, facilmente alvos de outros abusos, como por exemplo, econômico (FAVRETTO A, 2018), em que o agente alienador, via de regra, é membro da família.

Diante do exposto, tem-se promovidos reflexões e ações institucionais, dentre a qual destaca-se a subcomissão especial para reformular e atualizar o Estatuto do Idoso e a Política Nacional do Idoso, criada em 16 de maio de 2018 pela Comissão de Defesa dos Direitos da Pessoa Idosa, estando sob a presidência da deputada federal Carmen Zanotto. Um dos objetivos da subcomissão é o agrupamento de 130 projetos sobre o assunto, em grupos temáticos, a fim de identificar as proposições que sejam eficazes no aperfeiçoamento da legislação, como por exemplo, a atribuição de responsabilidade civil aos familiares de idoso que promoverem, em desfavor desse, abandono afetivo ou alienação parental (FERREIRA C, 2018).

Porém, a esfera familiar não pode continuar assumindo uma obrigação que também é do Estado, conforme já referido, mesmo que seja evidente indução normativa e social em prol daquela como melhor local para o idoso ter seus direitos garantidos, desconsiderando a complexidade desse instituto. Reflexo dessa extremada responsabilização, dentre outros, é a ineficiência de políticas públicas voltadas para proteção social das pessoas idosas (PEREIRA PAP, 2008).

Nesse sentido, Camarano AA e Kanso S (2010) ressaltam a necessidade de políticas públicas que promovam o deslocamento da responsabilidade familiar pela tutela da pessoa para estatal ou mesmo social, promovendo a inclusão do mercado privado na oferta e prestação de serviços. À exemplo do referido deslocamento, cita-se a Gerência de Atenção ao Idoso (GAl) e a Rede Nacional de Proteção e Defesa da Pessoa Idosa (RENADI), quais também auxiliam na promoção do princípio da dignidade da pessoa humana.

No pertinente às políticas públicas, embora sejam grandes as perspectivas em relação ao avanço no sistema de proteção a pessoa idosa, ainda é necessária uma maior instrumentalização em seus sistemas de formação, capazes de satisfazer as reais necessidades do que se encontram na fase da velhice, promovendo consequentemente, uma desoneração da responsabilidade das famílias no referido propósito.

\section{CONCLUSÃO}

A pessoa idosa, a partir de uma interpretação análoga do art. $2^{\circ}$ da Lei de Alienação Parental, poderá ser vítima de alienação quando for violentada, resultando no ceifamento de sua convivência familiar ou algum prejuízo psicológico. Neste caso, o agente alienador, a priori, poderá ser considerado familiar ou pessoa que tenha vínculo de afetividade. Entretanto, o Estado desde que comprovada sua omissão ou mesmo culpa pela violência dispensada a pessoa idosa, poderá ser responsabilizado, considerando sua obrigação de garantir à pessoa idosa, dentre outros, a proteção à vida e à saúde. Outrossim, embora a Consituição Federal 
estabeleça a garantia da família, sociedade e o Estado amparar as pessoas idosas, por si só, não garante a eficácia de suas normas, sendo necessária efetivação de políticas sociais públicas que proporcionem uma vida ou mesmo uma velhice digna.

\section{REFERÊNCIAS}

1. BRASIL. Constituição Federal de 1988. Brasília, 5 de outubro de 1988.

2. BRASIL. Lei 8.069/1990. Estatuto da criança e do adolescente, Brasília, 13 de julho de 1990.

3. BRASIL. Lei 10.741/2003. Estatuto do idoso, Brasília, 1o de outubro de 2003.

4. BRASIL. Portaria MS/GM no 737 de 16/5/01. Política nacional de redução da morbimortalidade por acidentes e violências, Brasília, 18 de maio de 2001.

5. BRASIL. Lei 12.318. Lei de alienação parental, Brasília, 26 de agosto de 2010.

6. BRASIL. Decreto-Lei no 4.657. Lei de Introdução às normas do direito brasileiro, Rio de Janeiro, 04 de setembro de 1942.

7. BRASIL.Tribunal de Justiça do Estado do Rio Grande do Sul (TJRS). Ementa: Agravo de instrumento. Idoso. ação declaratória de ocorrência de alienação parental. determinação de emenda à inicial para adequar fundamentos e pedidos ao estatuto do idoso. hipótese não prevista no rol taxativo do art. 1.015 do cpc. inadmissibilidade. É descabida a interposição de agravo de instrumento em face de decisão que determinou a emenda à inicial para alteração dos fundamentos e pedidos aos preceitos da Lei 10.741/03, por não se vislumbrar ser caso de aplicação analógica da lei de alienação parental. Agravo de instrumento no 70076907096 . Agravantes: S.B.M, A.M.N., D.B.M.L., C.A.B.M., e F.V.M.F. Agravada: M.M.P.S. Relator Des. Ricardo Moreira Lins Pastl. Porto Alegre, 08 de março de 2018.

8. BELLO FILHO NB. Sistema constitucional aberto. Belo Horizonte: Del Rey, 2003; 288 p.

9. CAMARANO AA, KANSO S. As instituições de longa permanência para idosos no Brasil. Revista Brasileira de Estudos da População, 2010; 27(1): 233-235.

10. CASTRO VC, RISSARDO LK, CARREIRA L. Violência contra os idosos brasileiros: uma análise das internações hospitalares. Revista Brasileira de Enfermagem, 2018; 71(suppl 2):777-785.

11. COELHO FU. Curso de direito civil: família, sucessões. 5. ed., rev. e atual. São Paulo: Saraiva, $2012 ; 360$ p.

12. DAHLBERG LL, KRUG EG. Violência: um problema global de saúde pública. Ciência e Saúde Coletiva, 2006; 11: 1163-1178.

13. DIAS MB. Manual de direito das famílias. 10. ed., rev. atual. e ampl. São Paulo: Revista dos Tribunais, 2015; 750p.

14. FAVRETTO A. Idosos também podem ser alvos de abuso por alienação parental? Disponível em https://www.semprefamilia.com.br/idosos-tambem-podem-ser-alvos-de-abuso-por-alienacao-parental/ Acesso em 10 de mar de 2019.

15. FERREIRA C. Comissão aprova relatório que sugere alterações no Estatuto do Idoso. Disponível em https://www2.camara.leg.br/camaranoticias/noticias/DIREITO-E-JUSTICA/569941-COMISSAO-APROVARELATORIO-QUE-SUGERE-ALTERACOES-NO-ESTATUTO-DO-IDOSO.html. Acesso em 16 de dez de 2018.

16. FRASER N, HONNETH A. Redistribution or recognition? : a political-philosophical Exchange. London: Verso, 2003; $288 \mathrm{p}$.

17. FREITAS AVS, NORONHA CV. Idosos vivendo em instituições de longa permanência: o paradoxo da proteção e dos maus tratos. In: FREITAS AVS, NORONHA CV (Org.) Violências intencionais contra grupo de vulneráveis crianças, adolescentes, adultos jovens, mulheres e idosos. Salvador: Edufba, 2012; 171 -179 p.

18. GOMES JLP. Síndrome da alienação parental: o bullying familiar. São Paulo: Imperium Editora e Distribuidora de Livros, 2014; $138 \mathrm{p}$.

19. GARDNER RAMD. O DSM-IV tem equivalente para o diagnóstico de síndrome de alienação parental (SAP)? Disponível em http://www.alienacaoparental.com.br/textos-sobre-sap-1/o-dsm-iv-tem-equivalente. Acesso em 10 de maio de 2017.

20. GONÇALVES, CR. Direito de família. 15 ed. São Paulo: Saraiva, 2015; 742p.

21. KRUG EG, et al. World report on violence and health. Geneva, World Health Organization, 2002. Disponível em https://www.opas.org.br/wp-content/uploads/2015/09/relatorio-mundial-violencia-saude.pdf. Acesso em 20 de mar de 2019.

22. LIMA AMM, SILVA HS, GALHARDONI R. Envelhecimento bem-sucedido: trajetórias de um constructo e novas fronteiras. Interface - Comunicação, Saúde, Educação, 2008; 12 (27): 795-807.

23. LOBO P. Direito civil: famílias. 4. ed. São Paulo: Saraiva, 2011; 437 p.

24. MADALENO R. Manual de direito de família. Rio de Janeiro: Forense, 2017, 616 p. 
25. MARQUES CL, MIRAGEM B. O novo direito privado e a proteção dos vulneráveis. 2. ed. São Paulo: Revista dos Tribunais, 2014; 239 p.

26. MIOTO RCT. Família e assistência social: subsídios para o debate do trabalho dos Assistentes Sociais. In: DUARTE MJO, ALENCAR MMT (Org.). Família e famílias: práticas sociais e conversações contemporâneas. Rio de Janeiro: Lumen Juris, 2010; $186 \mathrm{p}$.

27. MINAYO MCS. Múltiplas faces da violência contra a pessoa idosa. Mais 60: estudos sobre envelhecimento, 2014; 25(60): 10-27

28. MORAES MCB. Na medida da pessoa humana: estudos de direito civil constitucional. Rio de Janeiro: Renovar, 2010, $494 \mathrm{p}$.

29. OMS, 2002. Disponível em: https://www.who.int/eportuguese/countries/bra/pt/. Acesso em: 8 jun. 2018

30. PASINATO MTM, KORNIS GEM. A inserção dos cuidados de longa duração para idosos no âmbito dos sistemas de seguridade social: experiência internacional. In. CAMARANO AA, KANSO S (Org) Revista brasileira de estudos de população, 2010; 27(1):39-66.

31. PEREIRA AP. A nova constituição e o direito de família. Rio de Janeiro: Renovar, 1990; 158 p.

32. PEREIRA PAP. Política social: temas \& questões. São Paulo: Cortez, 2008; 216 p.

33. ROCHA CLA. O princípio da dignidade humana e a exclusão social. Revista do instituto brasileiro de direitos humanos,2016; 2: 49-67.

34. SAFFIOTI HIB. Gênero, patriarcado, violência. São Paulo: Fundação Perseu Abramo, 2004; $151 \mathrm{p}$.

35. SARTI C. Violência familiar: relações violentas e contexto social. In: LIMA ACS. Antropologia e direito: temas antropológicos para estudos jurídicos. Blumenau: LACED, 2012; 502-509p.

36. SOUZA VS, OLIVEIRA PO. O idoso vítima de alienação parental: a aplicação análoga da lei 12.318 de 2010 . Revista justiça \& sociedade,2018; 3 (1) :113-116.

37. TARTUCE F. Direito de família. 12 ed. rev.atual e ampl. Rio de Janeiro: Forense, 2017; 752 p.

38. TELES MAA, MELO M. O que e violência contra a mulher. São Paulo: Brasiliense, 2003;120p.

39. TEIXEIRA ACB, RODRIGUE RLA. Multiparentalidade como nova figura de parentesco na contemporaneidade. Revista brasileira de direito civil, 2015; 4: 9-38.

40. ZIMMERMANN A. Curso de direito constitucional. Rio de Janeiro: Lúmen Juris, 2002; 607 p. 